\title{
ELECTRICAL STIMULATION GUIDANCE FOR CERVICAL EPIDURAL PLACEMENT
}

Ban CH Tsui MD MSc FRCPC, Alese M Wagner BSc, Kendall Bateman MD, Martin Bouliane MD FRCPS, Jeffrey Bury MD FRCPS

Department of Anesthesiology and Pain Medicine, University of Alberta, 8-120 Clinical

Sciences Building, Edmonton, Alberta, T6G 2G3

\section{INTRODUCTION}

Cervical epidural anesthesia (CEA) has shown to provide excellent analgesia for patients undergoing upper extremity surgery. Many anesthesiologists are unfamiliar with direct epidural catheter placement. We hypothesize that low current electrical stimulation can be used to successfully guide epidural catheters from the thoracic region to the cervical area in adults undergoing upper extremity surgery. This would offer the benefits of CEA without the hazard of direct cervical placement.

\section{METHODS}

Following IRB approval, 10 adult patients presenting for total shoulder arthroplasty were studied. A $17 \mathrm{G}$ Tuohy needle was inserted into the thoracic space using a paramedian approach with loss of resistance. A nerve stimulator was connected to a $20 \mathrm{G}$ epidural catheter with a stylet and primed with saline. A 1-10mA current was applied through the catheter as it advanced cephalad into the epidural space. Muscle twitch was observed as the catheter threaded cranially. When the catheter was optimally positioned the presumed spinal level of the catheter was recorded, the stylet removed and the catheter secured. Xrays confirmed the location of the cervical catheter. An infusion of ropivacaine $2 \mathrm{mg} / \mathrm{ml}$ and morphine $0.05 \mathrm{mg} / \mathrm{ml}$ was used in 9 patients. One patient allergic to morphine received ropivacaine $2 \mathrm{mg} / \mathrm{ml}$ and fentanyl $2 \mu \mathrm{g} / \mathrm{ml}$. Infusion rates ranged from 2-8 $\mathrm{mL} / \mathrm{hr}$. Pain scores were collected over 72 hours.

\section{RESULTS}

The 10 patients studied were ASA I - III, $68.0 \pm 8.1$ years and an average of $88.0 \pm 19.0$ $\mathrm{kg}$. The average current to elicit a muscle response was $4.8 \pm 2.0$. All x-rays corresponded within 1-2 dermatomes of the muscle response.

\begin{tabular}{|c|c|c|c|c|c|c|}
\hline \multicolumn{7}{|c|}{ Pain Scores (Verbal Analog Scale 0-10) } \\
\hline Recovery Room & \multicolumn{2}{|c|}{ Day 1 } & \multicolumn{2}{c|}{ Day 2 } & \multicolumn{2}{c|}{ Day 3 } \\
\hline Rest & Rest & Activity & Rest & Activity & Rest & Activity \\
\hline $0.7 \pm 1.5$ & $0.3 \pm 0.9$ & $1.4 \pm 1.3$ & $0 \pm 0$ & $1.5 \pm 1.2$ & $0 \pm 0$ & $0.9 \pm 1.2$ \\
\hline
\end{tabular}

\section{DISCUSSION}

Low current epidural stimulation may be used to guide epidural catheters from the thoracic region to the cervical epidural space in adults undergoing total shoulder athroplasty. This epidural technique provided highly effective postoperative analgesia in a patient group with traditionally severe postoperative pain and in whom early mobilization is critical. 